\title{
James Kenneth (Ken) Champion, MD, FACS 15 Aug 1951-25 Sep 2016
}

Received: 17 November 2016/Published online: 21 November 2016

(C) Springer Science+Business Media New York 2016

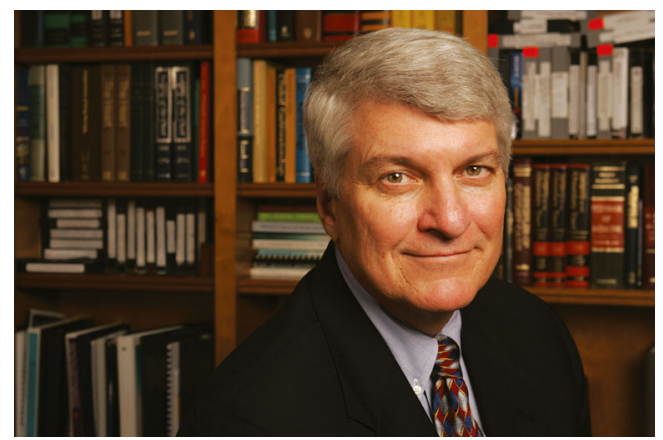

James Kenneth (Ken) Champion, MD, FACS, was a nationally recognized expert in videoscopic general and thoracic surgery. He was the son of Lorraine Champion and the late James Champion and was born on August 15, 1951, in Birmingham, Alabama. He grew up in Birmingham and was a 1969 graduate of Phillips High School. He received a baccalaureate degree in Chemistry from the University of Alabama and his Doctorate of Medicine from the University of Alabama Medical College. He served surgical residencies in Birmingham, Alabama, and Morgantown, West Virginia. Dr. Champion was also a Clinical Professor of Surgery of the Mercer University College until his retirement from private practice in 2011.

Dr. Champion was one of the first bariatric surgeons in Atlanta and founded the Videoscopic Institute of Atlanta in 1999. Dr. Champion was a Director of the Emory University Endosurgical Center from 1994 to 1996. He was a Director of Bariatric Surgery at the Emory-Dunwoody Medical Center from 2003 to 2006 and a Director of Bariatric Surgery at the Northside Hospital from 2007 to 2010. He was also a staff surgeon at various hospitals in Alabama, Georgia, and Tennessee during his medical career.

Ken was a Fellow of the American College of Surgeons, Leadership Society of American College of Surgeons, and Southeastern Surgical Congress. He was a member of the Society of Gastrointestinal Endoscopic Surgeons, the American Society of Metabolic and Bariatric Surgery, the International Federation for the Surgery of Obesity, the Atlanta Surgical Association, and the Society for Surgery of the Alimentary Tract. Dr. Champion wrote numerous surgical textbook chapters and was an Advisory Board Member of the American College of Surgeons Bariatric Surgery Center Network Accreditation Program.

Ken was married to Susan Mitchell Champion of Marietta, Georgia, who survives him. His children are Seth Champion, of Atlanta, Georgia; Victoria Champion of Weare, New Hampshire; and Gabriel Champion of Marietta, Georgia.

Ken was an avid collector of unique firearms and was a member of a local gun club. He was a talented painter and sculptor. He enjoyed gourmet cooking. His greatest loves were his family and pets. He also served on the homeowners' association board for the town of Seaside, Florida.

After an extended illness, Dr. Champion passed away at his home on September 25, 2016. Ken's wishes were to be cremated, and his remains were taken to the family's Seaside home where his ashes will be scattered in the Gulf of Mexico. At a later date, a celebration of Ken's life will be held at the family home in Marietta, Georgia.

Memorial gifts may be made to the ASMBS Foundation for obesity research, education, and access to care. To make an online donation or to download the donation form, please visit www.asmbsfoundation.org. 